\title{
Penerapan PSAK No.45 pada Laporan Keuangan Lembaga Masjid
}

\author{
Christin Dwi Novitasari ${ }^{1}{ }^{*}$, Yulinartati $^{2}$, Dania Puspitasari ${ }^{3}$
}

1,2,3 Jurusan Akuntansi, Fakultas Ekonomi, Universitas Muhammadiyah Jember

\section{A R T I C L E I N F O}

Article history:

Received 17 August 2018

Received in revised form

20 September 2018

Accepted 18 October 2018

Available online 25

November 2018

\section{Kata Kunci:}

Akuntansi, Laporan

keuangan, Organisasi

Nirlaba, PSAK No.45,

Institut masjid

Keywords:

Accounting, Financial

report, Nonprofit

Organization, PSAK No.45,

Institute of mosque

\begin{abstract}
A B S T RAK
Institusi masjid adalah organisasi nirlaba di bidang keagamaan. Lembaga masjid harus dan berhak membuat laporan keuangan yang bertanggung jawab dan melaporkan kepada pengguna laporan keuangan kelembagaan masjid. Penelitian ini bertujuan untuk mengetahui apakah pelaksanaan pelaporan keuangan Roudhotul Masjid Muchlisin telah sesuai dengan apa yang tercantum dalam PSAK No.45. Metode penelitian yang digunakan adalah metode analisis deskriptif yaitu penerapan laporan keuangan yang meliputi analisis pengakuan, pengukuran, pengungkapan dan pelaporan. Hasil penelitian ini menunjukkan bahwa laporan keuangan masjid Roudhotul Muchlisin masih dalam bentuk sederhana dalam bentuk pendapatan dan pengeluaran belum sesuai dengan PSAK No. 45 dalam ketiadaan tenaga akuntansi. Penyebab penghambatan penerapan PSAK No.45 ke masjid adalah karena sumber daya di bidang akuntansi masih kurang dan nama-nama pada laporan keuangan akun juga tidak sesuai dengan PSAK No.45 dan sulit dimengerti oleh pembaca.
\end{abstract}

\section{A B S T R A C T}

The mosque institution is a non-profit organization in the religious field. The mosque institution should and is entitled to make accountable financial statements and report to users of the mosque institutional financial statements. This study aims to determine whether the implementation of financial reporting Roudhotul Muchlisin Mosque has been in accordance with what is listed in PSAK No.45. The research method used is descriptive analysis method that is the application of financial statements that include analysis of the recognition, measurement, disclosure and reporting. The results of this study indicate that the financial statements of the mosque Roudhotul Muchlisin still in the form of simple in the form of income and expenditure not yet in accordance with PSAK No. 45 in the absence of accounting personnel. The cause of inhibiting the application of PSAK No.45 to the mosque is because the resources in the field of accounting are still lacking and the names on the financial statement account are also not in accordance with PSAK No.45 and difficult to understand by the reader.

\footnotetext{
* Corresponding author.

E-mail addresses: christinnovitasari0202@gmail.com (Christin Dwi Novitasari)
} 


\section{Pendahuluan}

Sejalan dengan perkembangan masyarakat, berkembang pula organisasi yang disebut organisasi nirlaba, yaitu organisasi yang dalam operasinya tidak berorientasi untuk menghasilkan laba. Pada umumnya organisasi jenis ini menekankan pada pelayanan sebaik-baiknya pada pihak external, misalnya organisasi pelayanan, kesehatan, layanan social dan keagamaan (A.Bachrum, 2005). Organisasi nirlaba memperoleh modalnya sendiri atau fund capital dengan cara memperbesar surplus yang diperoleh, menerima sumbangan atau bantuan dan donasi dari individu atau kelompok masyarakat. Pada dasarnya, ilmu akuntansi dan praktek akuntansi di lingkungan bisnis telah menjadi bagian yang integral. Namun, ilmu akuntansi dan prakteknya di luar entitas bisnis khususnya lembaga keagamaan sangat terintegralkan. Sebagai entitas pelaporan akuntansi yang menggunakan dana masyarakat sebagai sumber keuangan dalam bentuk sumbangan, sedekah atau bentuk bantuan lainnya yang berasal dari masyarakat (publik) (Angelia, 2014).

Simanjuntak dan Januarsi (2011) menyatakan bahwa entitas masjid jarang sekali menjadi perhatian peneliti akuntansi sebelumnya padahal organisasi nirlaba seperti organisasi Masjid yang memperoleh sumber dana dari sumbangan para donatur, justru harus menjadi prioritas mengenai transparansi dan akuntabilitas organisasi masjid tersebut. Sumber dana yang diperoleh oleh masjid dapat berasal dari donasi, kotak amal yang bisa juga dikatakan zakat, infaq dan shodaqoh atau yang lainnya dari masyarakat (Ayub, 2007). Dari sumber dana tersebut takmir seharusnya dapat menyajikan laporan posisi keuangan yang menyediakan informasi mengenai aktiva, kewajiban, dan informasi lain yang diperlukan dalam pertanggung jawaban. Karena yang kita ketahui biasanya masjid hanya menyajikan laporan keuangan sederhana seperti laporan infaq yang biasanya dilaporkan sekali dalam seminggu (Berlina 2004). Pengurus masjid yang dapat dipercaya tidak akan melalaikan tugasnya mengingat keuangan masjid diperoleh dari sedekah jamaah. Tanpa pertanggungjawaban yang jelas dan rinci akan menimbulkan fitnah di kalangan masyarakat (Bastina, 2007).

Pengelolaan sumber dana masjid merupakan hal yang sangat penting untuk diteliti dan dievaluasi khususnya dalam hal penyajian laporan keuangan. Dalam melakukan penyusunan laporan keuangan masjid Ikatan Akuntansi Indonesia (IAI) mempunyai peranan penting sebagai pembentuk standar akuntansi keuangan secara tertulis dengan menerbitkan PSAK 45. Menurut PSAK 45 (2011) mengatur tentang pelaporan keuangan organisasi nirlaba mengingat lembaga masjid juga termasuk dari organisasi nirlaba karena dalam menjalankan aktivitasnya tidak mendapatkan laba. Dan juga kriteria dari organisasi nirlaba hampir sama dengan kriteria masjid yaitu sumber dana berasal dari penyumbang, menghasilkan barang atau jasa tanpa bertujuan mendapatkan laba dan tidak adanya kepemilikan (Harap, 2007). Standar pelaporan dibuat dengan tujuan agar pelaporan keuangan organisasi nirlaba dapat lebih dipahami, memiliki relevansi dan memiliki daya banding yang tinggi. Laporan keuangan nirlaba meliputi Laporan Posisi Keuangan, Laporan Aktivitas, Laporan Arus Kas, dan Catatan Atas Laporan Keuangan (Rukma, 2009).

Masjid Roudhotul Muchlisin yang berada di Jl. Gajah Mada no.180 Jember. Struktur kepengurusan, Organisasi pengurus masjid atau takmir masjid berada di naungan Yayasan masjid Roudhotul Muchlisin. Sumber dana masjid berasal dari shodaqoh dari orang-orang, dari infaq,kotak amal,dan juga sumbangan dari para donatur. Sumber dana tersebut digunakan untuk kesejahteraan masjid dan kegiatan masjid. Dana yang di dapat yaitu Infaq Minggu sebesar 686.000, Sodaqoh Pengajian Muslimat sebesar Rp 1.000.000, Sodaqoh Akad Nikah sebesar Rp 200.000, Infaq Jum'at sebesar Rp 17.022.000, Biaya Qori' sebesar Rp 450.000, Kotak Amal tiap minggu sebesar Rp 850.000. Laporan keuangan masjid Rouhdotul Muchlisin di jember masih sangat sederhana dan masih dalam bentuk dua lajur yaitu lajur pemasukan dan pengeluaran, belum menerapkan laporan keuangan yang sesuai dengan standar akuntansi keuangan yang ada di Indonesia.

Pengurus masjid harus memperhatikan masalah pengelolaan keuangan masjid jika dapat dilaksanakan dengan baik pengurus masjid dapat dipercaya (Lingga, 2014). Dengan makin berkembangnya peralatan, budaya, sosial dan ekonomi diperlukan konsep manajemen masjid yang jelas dan laporan keuangan yang transparan sesuai dengan syariat Islam. Berdasarkan hasil keuangan pengurus masjid Roudhotul Muchlisin melakukan pencatatan segala transaksi yang ada dengan menggunakan Accrual base metodh, bendahara yang membuat laporan keuangan pada masjid tersebut belum mengerti tentang PSAK 45 pada laporan keuangan entitas nirlaba sehingga hanya membuat laporan keuangan yang sederhana. Masjid roudhotul muchlisin belum menerapkan PSAK 45 terlihat dari tidak adanya laporan aktivitas, laporan arus kas, catatan atas laporan keuangan. Ada beberapa hal yang perlu diperhatikan dalam penyajian laporan keuangan masjid yang telah diterapkan oleh masjid Roudhotul Muchlisin yang telah berjalan selama kurang lebih satu tahun, Yakni pencatatan masalah biaya yang seharusnya dimasukkan dalam kolom pengeluaran dan tidak menganggap biaya sebagai penerimaan 
kas atau uang masuk untuk masjid Roudhotul Muchlisin. Sehingga apabila masjid Roudhotul Muchlisin menerapkan penyajian laporan keuangan yang sesuai dengan PSAK 45 maka, akan mempermudah donatur untuk membaca laporan keuangan tersebut. Tidak menyesatkan pengguna laporan keuangan. Dampaknya mengalami penururnan pendapatan tiap minggunya, dan kurangnya kepercayaan donatur.

\section{Metode}

Penelitian ini termasuk dalam penelitian kualitatif dengan pendekatan analisis deskriptif, Metode deskriptif analisis merupakan metode penelitian dengan cara mengumpulkan data-data sesuai dengan yang sebenarnya kemudian data-data tersebut disusun, diolah dan dianalisis untuk dapat memberikan gambaran mengenai masalah yang ada. Sugioyono (2016).

Berdasarkan pendekatan ini peneliti akan mengumpulkan, mempersiapkan, serta menganalisis data berupa laporan keuangan yang ada pada masjid yang nantinya akan memberikan gambaran yang jelas mengenai penerapan PSAK 45 pada laporan keuangan lembaga masjid Roudhotul Muchlisin di jember.

Data yang di gunakan dalam penelitian ini adalah data primer dan data sekunder. Data primer secara khusus dikumpulkan oleh peneliti untuk menjawab pertanyaan penelitian. Dimana data ini di peroleh melalui secara langsung melalui wawancara dan observasi yaitu mengenai penerapan PSAK 45 kepada takmir masjid. Data sekunder dalam penelitian ini adalah berupa laporan keuangan, struktur kepengurusan, gambaran tentang latar belakang pada Masjid Roudhotul Muchlisin di Jember.

Metode yang digunakan peneliti dalam pengumpulan data adalah Wawancara dan Dokumentasi. Peneliti melakukan wawancara dengan pihak kepengurusan pada masjid terutama kepada bendahara yang mempunyai tanggung jawab terhadap laporan keuangan masjid. Sugiyono (2016) menyebutkan bahwa dokumen merupakan catatan peristiwa yang sudah berlalu. Dokumen bisa berbentuk tulisan, gambar, atau karya-karya monumental dari seseorang. Dalam hal ini, peneliti mencoba mendapatkan informasi yang terkait dengan permasalahan penerapan PSAK 45 pada laporan keuangan lembaga masjid. Selain itu juga mengumpulkan data dan informasi melalui buku-buku, jurnal-jurnal, internet dan dengan melakukan penelitian terhadap dokumen dan laporan keuangan pada masjid.

Pada penelitian ini terdapat beberapa tahap analisis yaitu sebagai berikut : a) Pengumpulan data, yaitu mengumpulkan data di lokasi penelitian dengan observasi, wawancara, dan dokumentasi dengan menentukan strategi pengumpulan data yang tepat, b) Mengidentifikasi data laporan keuangan yang telah di terapkan di Masjid Roudhotul Muchlisin yang sesuai dengan PSAK 45, c) Merekontruksi data laporan keuangan yang telah diterapkan oleh Masjid Roudhotul Muchlisin disusun kembali sebagaimana diterapkannya laporan keuangan masjid yang sesuai dengan PSAK 45, d) Menyimpulkan hasil penelitian yang telah dilakukan pada Masjid Roudhotul Muchlisin

\section{Hasil dan pembahasan}

Masjid roudhotul Muchlisin yang berada di jalan Gajah Mada no. 180 kecamatan Kaliwates, Jember di bangun pada tahun 1978. Masjid Roudhotul Muchlisin dahulu merupakan masjid yang sangat sederhana. Pada tanggal 10 maret 2010 masjid ini direnovasi dan mulai penggalian tanah pertama oleh K.H. Mursyid. Pada tanggal 13 maret 2010. Masjid Roudhotul Muchlisin dengan luas tanah sekitar 1000 meter persegi, yang memiliki dua lantai mampu menampung sekitar 2500 jamaah. Masjid tersebut juga membangun menara yang di fungsikan sebagai perpustakaan dan bagi musafir yang melewati jember untuk tempat peristirahatan. Di sana juga ada sebuah kuliner Food Corner "Maqha Azzahra". Selain digunakan sebagai tempat ibadah, masjid itu juga digunakan untuk acara akad nikah dan kajiankajiankeislaman.

Tabel 1. Laporan Keuangan Masjid Per 31 April 2017

\begin{tabular}{llllc}
\hline NO & \multicolumn{1}{c}{ KETERANGAN } & PEMASUKAN & PENGELUARAN & SALDO \\
\hline & SALDO BANK & & & Rp 744.349.458 \\
& Pembukaan rekening & bank BNI & & \\
3 & Syariah & Rp 482.000 & & \\
3 & Infaq & Rp 36.791.500 & & \\
4 & Biaya akad & Rp 2.150.000 & Rp16.495.700 & \\
5 & Biaya operasional & & & Rp 767.277.258 \\
& JUMLAH SALDO & & & \\
\hline
\end{tabular}


Sumber : Masjid Roudhotul Muchlisin Jember

Tabel 2. Laporan Posisi Keuangan

\begin{tabular}{|c|c|c|c|}
\hline Keterangan & $\mathrm{Rp}$ & Keterangan & $\mathrm{Rp}$ \\
\hline Asset & & Liabilitas & \\
\hline Kas & Rp 608.558.971 & Utang jangka pendek & - \\
\hline \multicolumn{4}{|l|}{ Kas di bank: } \\
\hline Bank Jatim & Rp 29.533.600 & Utang jangka panjang & - \\
\hline Bank BNI & $\operatorname{Rp} \quad 47.759 .600$ & & \\
\hline Bank BNI Syariah & $\mathrm{Rp} 98.844 .300$ & Jumlah Liabilitas & - \\
\hline \multicolumn{4}{|l|}{ Aset tetap : } \\
\hline Tanah & Rp 350.000.000 & & \\
\hline Bangunan & Rp 290.000.000 & & \\
\hline Akm.penyusutan & $\operatorname{Rp}(26.000 .000)$ & & \\
\hline bangunan & Rp 220.000 .000 & & \\
\hline Menara & $\operatorname{Rp}(9.750 .000)$ & & \\
\hline Akm.penyusutan menara & Rp 60.000 .000 & & \\
\hline Peralatan & $\operatorname{Rp}(13.375 .000)$ & & \\
\hline Akm.penyusutan & & Saldo & \\
\hline \multirow[t]{8}{*}{ peralatan } & & Jumat & Rp $\quad 770.697 .600$ \\
\hline & & Istigosah & 18.231 .600 \\
\hline & & Minggu & 36.602 .800 \\
\hline & & Dana Infaq Idul Fitri & 48.898 .000 \\
\hline & & Dana Infaq Idul Adha & 28.861 .600 \\
\hline & & Shodaqoh & 868.591 .562 \\
\hline & & Jumlah Dana & Rp 1.771.883.162 \\
\hline & & Jumlah Liabilitas & \\
\hline Jumlah Asset & Rp 1.525.229.062 & Saldo Dana & Rp 1.771.883.162 \\
\hline
\end{tabular}

Laporan keuangan Masjid Roudhotul Muchlisin menurut PSAK 45

Laporan Posisi Keuangan yang dibuat oleh Masjid Roudhatul Muchlisin Kabupaten Jember belum menerapkan PSAK Nomor 45 dalam membuat laporan keuangan masjid. Maka dari itu saya merekontruksi laporan keuangan masjid yang sesuai dengan PSAK 45 yang terdiri dari dari Asset Lancar, Liabilitas Jumlah Dana.

Tabel 3. Laporan Aktivitas

\begin{tabular}{ll}
\hline \multicolumn{2}{c}{ Pendapatan dan penghasilan } \\
\hline Pendapatan Dan Penghasilan & $\mathbf{5 1 4 . 3 3 4 . 9 9 6}$ \\
Pendapatan Food Corner “Maqha Azzahra” & 113.083 .393 \\
Sumbangan sodaqoh akad & 25.100 .000 \\
Sumbangan sodaqoh pengajian & 1.500 .000 \\
Sodaqoh lain - lain & 372.651 .600 \\
Penghasilan investasi lain - lain & 1.999 .967 \\
Total Pendapatan Dan Penghasilan & $\mathbf{5 1 4 . 3 3 4 . 9 9 6}$ \\
Biaya Dan Kerugian & 456.580 .855 \\
Biaya operasional masjid dan gaji karyawan & 27.000 .000 \\
Beban kurban tahun 2017 & 27.523 .600 \\
Beban listrik & 511.104 .455 \\
Total biaya dan kerugian & $\mathbf{5 1 1 . 1 0 4 . 4 5 5}$ \\
Kenaikan Jumlah Aset Netto Tidak Terikat & $\mathbf{3 . 2 3 0 . 5 1 1}$ \\
\hline
\end{tabular}

Laporan Aktivitas Masjid Roudhotul Muchlisin Jember menurut PSAK 45 
Masjid Roudhotul Muchlisin masih belum membuat laporan aktivitas karena masih belum ada tenaga ahli akuntansi dalam menyusun laporan aktivitas yang sesuai dengan PSAK No.45. Belum ada perubahan Aset Neto Terikat Temporer di masjid roudhotul muchlisin jember.

Tabel 4. Laporan Arus Kas

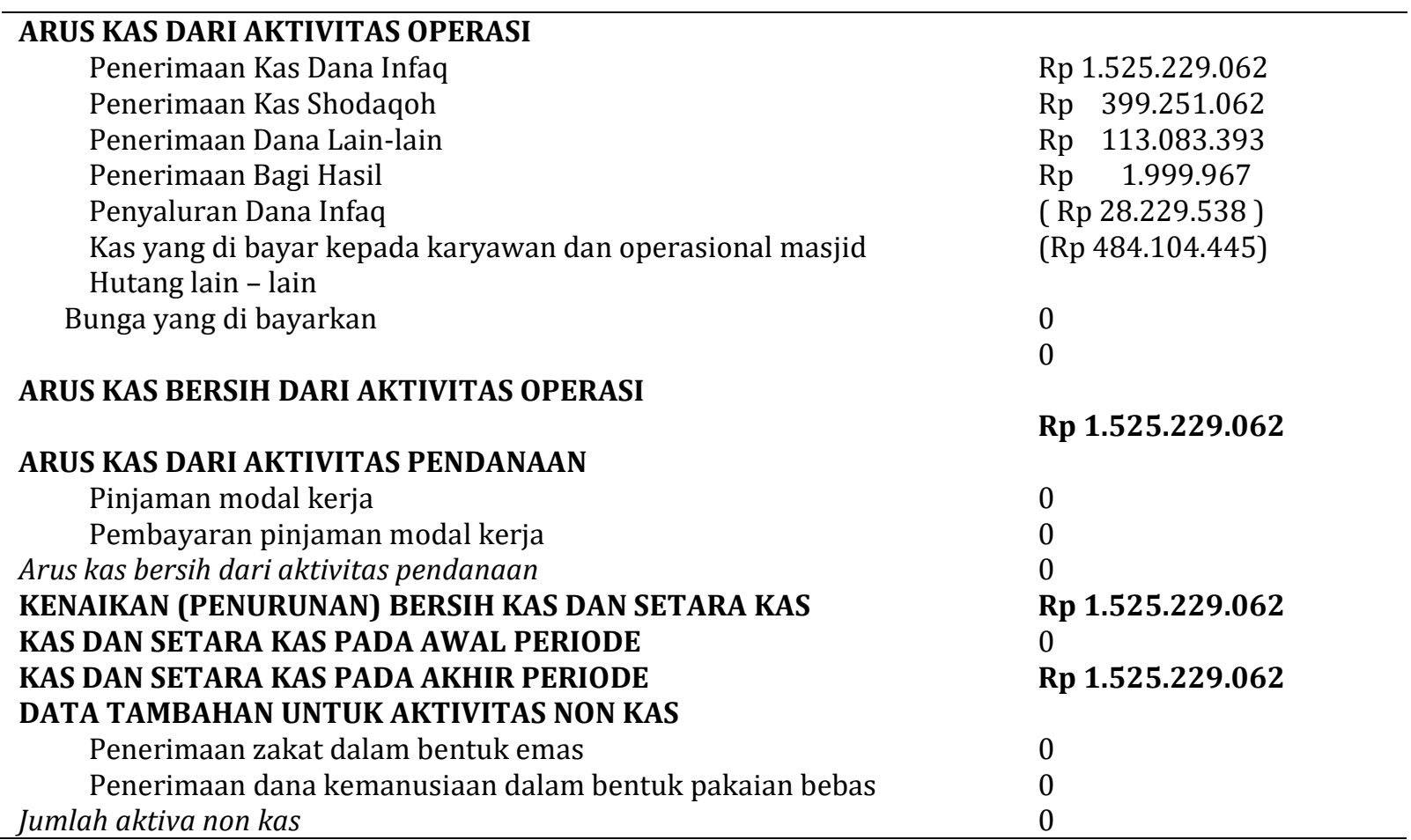

Laporan Arus Kas Masjid Roudhotul Muchlisin menurut PSAK 45

Masjid Roudhotul Muchlisin jember masih belum membuat laporan arus kas, karena masih terbatas tenaga ahli dalam menyusun laporan arus kas.

1. Catatan Atas Laporan Keuangan

Catatan atas laporan keuangan merupakan catatan yang menjelaskan mengenai gambaran umum organisasi, ikhtisar kebijakan akuntansi, serta penjelasan pos-pos laporan keuangan dan informasi penting lainnya. Dilihat dari rekonstruksi laporan keuangan Masjid Roudhotul Muchlisin yang dibuat belum mengacu pada PSAK No. 45.

Dengan laporan keuangan yang telah ditampilkan dan dipublikasi seperti ini memang cukup mudah dipahami oleh masyarakat umum (donator), karena sudah cukup transparan dalam melaporkan keuangan kepada masyarakat. Laporan keuangan Masjid Roudhotul Muchlisin diterbitkan dalam periode setiap minggu. Laporan keuangan setiap minggu ditujukan untuk pihak internal dan untuk masyarakat umum (donatur) sebagai bentuk akuntabilitas.

Catatan atas laporan keuangan meliputi penjelasan naratif atau rincian jumlah yang tertera dalam laporan posisi keuangan, laporan aktivitas, dan laporan arus kas serta informasi tambahan seperti kewajiban kontinjensi dan komitmen. Catatan atas laporan keuangan juga mencakup informasi yang diharuskan dan dianjurkan untuk diungkapkan dalam Pernyataan Standar Akuntansi Keuangan serta pengungkapan-pengungkapan lain yang diperlukan untuk menghasilkan penyajian laporan keuangan secara wajar. Laporan Keuangan Masjid Roudhotul Muchlisin belum menerapkan PSAK No.45 laporan keuangannya masih dalam bentuk sederhana yaitu pemasukan dan pengeluaran. Setelah penelitian ini Masjid Roudhotul Muchlisin dapat membuat Laporan Keuangan ynag sesuai dengan PSAK No.45.

\section{Simpulan dan saran}

Dari hasil penelitian yang diperoleh maka dapa disimpulan yatu: (1) Laporan keuangan masjid disajikan sangat sederhana, dengan pemasukan dan pengeluaran; (2) Berdasarkan pengamatan yang telah dilakukan peneliti memperlihatkan bahwa penyajian informasi keuangan masjid sebagai bentuk akuntabilitas dan transparansi telah dilakukan dengan dua cara yaitu: Diumumkan setiap minggu yaitu tepat pada pelaksanaan sholat jum'at dan Ditempel dipapan informasi yang telah disediakan oleh 
pengurus masjid Masjid Roudhotul Muchlisin; Setelah menganalisis laporan keuangan yang dilakukan pengurus masjid Roudhotul Muchlisin tidak sesuai dengan standar keuangan PSAK No.45. Karena sangat sederhana yaitu bentuknya yang masih menggunakan metode accrual basic dengan pencatatan pemasukan dan pengeluaran.

Adapun saran peneliti yang mungkin bermanfaat pada masjid: (1) Mendorong konsistensi penggunaan akuntansi sebagai instrumen untuk mendorong kejujuran dan akuntabilitas akan menggeser pemahaman menjaga kehormatan diri, wibawa dan citra kepemimpinan pengurus masjid Roudhotul Muchlisin; (2) Sebaiknya bentuk laporan keuangan disesuaikan dengan PSAK No.45 serta lengkapi setiap data laporan keuangan dengan catatan atas laporan keuangan; (3) Konstruk yang dihasilkan peneliti agar menjadi bahan untuk pembelajaran bagi pengurus masjid dalam mengelola laporan keuangan.

\section{Daftar Rujukan}

A. Bachrun Rifa'I dan Moch. Fakhruroji, Manajemen Masjid, Bandung : Benang Merah Press, 2005

Angelia Novrina M.T. 2014. Penerapan Laporan Keuangan Organisasi Nirlaba Berdasarkan Psak No 45 Pada Panti Sosial Tresna Werdha Hana Universitas Sam Ratulangi Manado. Skripsi

Ayub, Moh E. Dan Muhsin. Rahman Mardjoned. 2007. Manajemen Masjid Petunjuk Praktis Bagi Para Pengurus. Cetakan kesembilan. Jakarta : Gema Insani.

Barliana.M.S.,2004, “Tradisionalitas Dan Modernitas Tipologi Arsitektur Masjid”, Jurnal Terakreditasi Nasional Dimensi Teknik Arsitektur. Vol.32, No.2.

Bastian Indra , 2007, Akuntansi Yayasan dan Lembaga Publik, Yogyakarta, Penerbit Erlangga.

Harap, Sofyan Syahri, 2007. A Statement of Basic Accounting Theory (ASOBAT). Jakarta. Penerbit PT. Raja Grafindo Persada.

Lingga , Jenar Wijangsongko (2014) Implementasi Akuntansi Dalam Organisasi Keagamaan Di masjid Istiqomah UPN “VETERAN" Jawa Timur.

Rukmana ,Nana. Manajemen Masjid Panduan Praktis Membangun Dan Memakmurkan Masjid. Bandung : MQS Publishing, 2009.

Simanjuntak, D.A dan Januarsi, Y. 2011, “Akuntabilitas dan Pengelolaan Keuangan Di Masjid”. Jurnal Simposium Nasional Akuntansi, Vol. 14, No.7. Skripsi

Sugiyono, 2016. Metode Penelitian Kuantitatif, Kualitatif dan R\&D. Bandung, PT. Alfabeta. 